\title{
A agenda ambiental na administração pública (A3P) versus políticas socioambientais no Brasil: caracterização e desafios
}

Em meio à profunda e complexa crise socioambiental que afeta os mais diversos aspectos da vida humana, emerge a necessidade de revisão dos atuais padrõe de produção e consumo da sociedade. No âmbito da Administração Pública, a Agenda Ambiental na Administração Pública (A3P) surgiu como uma das principais estratégias do Governo Federal Brasileiro para inserção de critérios de sustentabilidade em suas atividades. Nesta perspectiva, este ensaio teórico tem como objetivo analisar o programa A3P sob a ótica das políticas públicas socioambientais no âmbito Federal Brasileiro. As bases teóricas do manuscrito foram construídas a partir de pesquisas do tipo bibliográfica e documental e os resultados mais relevantes do estudo indicaram que o programa A3P constitui uma importante ferramenta estratégica para a efetivação de políticas públicas socioambientais, embora sejam muitos os desafios para a ampliação de sua usabilidade, a exemplo dos desalinhamentos dos modelos de gestão existes no Brasil.

Palavras-chave: Sustentabilidade; Gestão pública; Responsabilidade socioambiental; Política estatal.

\section{The environmental agenda in public administration (A3P) versus social-environmental policies in Brazil: characterization and challenges}

\begin{abstract}
In the context of deep and complex socioenvironmental crisis affecting various aspects of human life, emerges a need for society's current production and consumption patterns review. Relating to Public Administration, the Environmental Agenda in Public Administration (A3P) has emerged as one of the Brazilian Federal Government main strategies for the insertion of sustainability criteria in its activities. In this perspective, this theoretical essay aims to analyze the A3P program from the socioenvironmental public policies' optics within Federal Brazilian scope. The manuscripts' theoretical basis were constructed from bibliographical and documentary research and the most relevant results indicated that the A3P program is an important strategic tool for socioenvironmental public policies effectuation, although there are many challenges for its usability expansion, as the example the existing Brazilian management models misalignments.
\end{abstract}

Keywords: Sustainability; Public administration; Socioenvironmental responsibility; State policy.

Topic: Gestão Pública

Reviewed anonymously in the process of blind peer
Received: 22/01/2017

Approved: 22/03/2017
Jailson de Arruda Almeida

Instituto Federal de Pernambuco, Brasil

http://lattes.cnpq.br/9210457908444449

jailsonaalmeida@hotmail.com

Suiane Valença Brandão

Universidade Federal Rural de Pernambuco, Brasil

http://lattes.cnpq.br/9055757760457782

suiane@yahoo.com.br
Referencing this:

ALMEIDA, A. J.; BRANDÃO, V. S.; PEDROSA, A. J. F.. A agenda ambiental na administração pública (A3P) versus políticas socioambientais no Brasil: caracterização e desafios. Revista Brasileira de Administração Científica, v.8, n.1, p.236-254, 2017. DOI: http://doi.org/10.6008/SPC2179-684X.2017.001.0018 


\section{INTRODUÇÃO}

A partir do final do século XX, com o agravamento dos problemas que passaram a afetar a vida humana - sobretudo no que se referem aos aspectos econômicos, sociais, políticos, ambientais e tecnológicos - o homem passou a se deparar com a real ameaça de sua extinção (CAPRA, 2005). Nesse sentido, debates e reflexões a respeito de modelos alternativos de desenvolvimento culminaram com a proposta do desenvolvimento sustentável, que, segundo Cavalcanti (2004), pressupõem a promoção da economia e do bem-estar dos seres humanos sem causar estresses que o sistema ecológico não consiga absorver.

Um dos grandes desafios enfrentados pela sociedade contemporânea diz respeito à implementação de um desenvolvimento pautado em bases sustentáveis, partindo do âmbito global para individual e proporcionando uma maior integração entre os aspectos econômicos, sociais e naturais do processo de desenvolvimento (VEIGA, 2005). Veiga (2005) destaca que isto não é algo possível de ocorrer em curto prazo, tampouco isoladamente. Nesta perspectiva, o alcance do desenvolvimento sustentável envolve a junção de esforços responsáveis dos diversos agentes envolvidos no processo: econômicos, sociais, políticos, culturais, ambientais e tecnológicos.

Ademais, as ideias de responsabilidade socioambiental vêm sendo amplamente discutidas no âmbito global, com vistas à construção de um desenvolvimento sustentável para as nações, e abrange a obrigação que um indivíduo ou organização tem diante sociedade e do meio ambiente, consequente de suas ações, que podem ter impacto positivo ou não (LUIZ et al., 2013). No âmbito das organizações, cada vez mais tem se difundido a necessidade de tais entidades realizarem ações além das exigências legais, assumindo uma postura de voluntárias em iniciativas e propostas que assegurem a manutenção do meio ambiente saudável para ser usufruído pelas gerações futuras (DIAS, 2011).

Na hodiernidade, emerge a necessidade de se repensar o Setor Público como entidade que precisa servir de exemplo nas práticas de responsabilidade socioambiental, considerando as demandas existentes na sociedade, constituída por cidadãos cada vez mais conscientes e exigentes (COELHO, 2012). Em resposta a tais demandas, Peccatiello (2011) afirma que são necessárias intervenções político-administrativas e mudanças através do aparato legal e da formulação e implantação de políticas públicas. Por outro lado, existem demandas mais globais que foram oficializadas a partir de acordos e legislações internacionais que devem ser cumpridos por meio de políticas públicas em cada nação participante, cujo contexto abrange também o Brasil.

Para Secchi (2010), política pública é uma diretriz elaborada para o tratamento ou a resolução de um problema considerado como coletivamente relevante. Em outras palavras, são orientações constituídas de uma intencionalidade política e que procuram responder a um problema público. Quando associadas às questões socioambientais, passam a designar políticas que objetivam atender, simultaneamente, aos problemas sociais, ambientais, econômicos, tecnológicos e culturais da sociedade (SANTILLI, 2005).

Diante da necessidade da Administração Pública de desenvolver programas, projetos e implantar iniciativas de responsabilidade socioambiental em suas instituições, os órgãos públicos passaram a buscar 
desempenhar um papel estratégico na inserção de critérios de sustentabilidade em suas atividades meio e finalísticas, sobretudo devido ao excessivo consumo de bens e serviços e à responsabilidade que possuem face ao cumprimento das políticas públicas (BRASIL, 2009).

Nesse contexto, uma das principais estratégias desenvolvidas pelo Governo Federal voltada à inserção de critérios de sustentabilidade nas atividades administrativas e operacionais é a Agenda Ambiental na Administração Pública (A3P), que é um programa que tem como objetivo promover uma reflexão sobre os atuais padrões de produção e consumo, por meio da adoção de ações relacionadas ao uso racional dos recursos naturais e bens públicos, à gestão adequada dos resíduos, à qualidade de vida no trabalho, à sensibilização e capacitação dos servidores e às licitações sustentáveis.

Os princípios norteadores do programa se encontram em harmonia com importantes legislações e políticas públicas que dispõem sobre valores e práticas de gestão socioambiental, corroborando a sua relevância. Além disso, a adesão dos órgãos públicos à A3P, nas esferas estadual e municipal da Federação, proporciona inúmeros benefícios, como o aumento da eficiência e da economia de recursos, a redução de desperdícios, a melhoria da qualidade de vida no trabalho, maior satisfação no trabalho e elevação do desempenho dos servidores públicos (ABREU et al., 2012).

Ante o exposto e considerando a relevância do programa A3P para a mitigação dos problemas socioambientais oriundos das atividades dos órgãos públicos, o presente artigo tem como objetivo analisar o programa A3P sob a perspectiva das políticas públicas socioambientais no âmbito federal brasileiro, abordando suas principais características e os desafios face à ampliação da usabilidade do programa nas entidades que compõem a esfera pública.

\section{METODOLOGIA}

Nessa perspectiva, este manuscrito se trata de um ensaio teórico em torno da utilização da ferramenta estratégica A3P pela Administração Pública e está estruturado de modo a: apresentar os aspectos centrais do programa A3P; descrever as principais políticas públicas e legislações federais que fundamentam a A3P; e demonstrar como as ações associadas aos eixos temáticos da A3P se relacionam com os objetivos centrais de tais políticas públicas e legislações.

\section{DISCUSSÃO TEÓRICA}

\section{Aspectos centrais da agenda ambiental na administração pública (A3P)}

A responsabilidade socioambiental na Administração Pública se inicia a partir do momento em que os órgãos que a compõem, por meio de seus gestores e demais indivíduos envolvidos, decidem transformar a realidade na qual estão inseridos e passam a exigir mudanças de atitudes e práticas em prol de um desenvolvimento sustentável (BRASIL, 2009). Nesse sentido, a A3P, enquanto programa de caráter voluntário que se destina a inserir critérios socioambientais nas atividades realizadas pelas entidades integrantes da esfera governamental, surge como uma proposta que visa redirecionar as ações do Governo Federal para a 
adoção de uma nova cultura institucional, que favoreça a incorporação de critérios socioambientais nas suas atividades diárias (BRASIL, 2009).

\section{Apresentação e eixos temáticos da A3P}

No Brasil, a gestão pública socioambiental é representada pela A3P, que surgiu em 1999, como um projeto do MMA voltado à incorporação de princípios da responsabilidade socioambiental nas atividades administrativas e operacionais dos órgãos que compõem a Administração Pública. Seu objetivo é criar uma cultura institucional voltada à inserção de práticas e valores sustentáveis no âmbito governamental (BRASIL, 2009).

O programa A3P encontra-se fundamentado nas recomendações do Capítulo IV da Agenda 21, que trata da mudança dos padrões de consumo e contempla: 1) o exame dos padrões insustentáveis de produção e consumo; e, 2) o desenvolvimento de políticas e estratégias nacionais de estímulo a mudanças nos padrões insustentáveis de consumo (BRASIL, 2001). Nessa perspectiva, a Agenda destaca que a mudança dos padrões de consumo exige múltiplas estratégias, focadas na demanda, no atendimento das necessidades dos pobres e na redução do desperdício e utilização dos recursos nos processos produtivos.

As estratégias sugeridas são (BRASIL, 2001): estimular o uso mais eficiente da energia e dos recursos; reduzir os resíduos ao mínimo, estimulando a reciclagem, a introdução de novos produtos ambientalmente saudáveis; usar o poder de compra dos governos para estimular padrões de consumo e produção ambientalmente saudáveis; estabelecer políticas de preços que incorporem os custos ambientais, fornecendo indicações aos consumidores e produtores sobre estes custos; e reforçar os valores que apoiam o consumo responsável por meio da educação, de programas de esclarecimento público, publicidade de produtos ambientalmente saudáveis.

Em 2002, a A3P foi reconhecida pela Organização das Nações Unidas para a Educação, Ciência e Cultura (UNESCO), em virtude de sua relevância e dos resultados positivos alcançados a partir de sua implantação. Nesse mesmo ano, o projeto foi elevado à categoria de programa, voltado à conscientização e sensibilização dos gestores públicos (BRASIL, 2007). A partir de então, a A3P passou a ser ação integrante do Plano Plurianual (PPA) para os anos 2004/2007 e 2008/2011. Deste modo, foram assegurados recursos para viabilização e implantação do programa nos órgãos públicos, tornando-o referência de sustentabilidade no setor público. Desde 2007, a A3P vem sendo fortalecida enquanto Agenda de Responsabilidade Socioambiental do Governo (BRASIL, 2007).

Diante da importância que os órgãos públicos têm em servir de exemplo para a minimização dos impactos socioambientais, os princípios da A3P são inspirados na Política dos 5R's: Repensar, Reduzir, Reaproveitar, Reciclar e Recusar consumir produtos que gerem impactos sociais e ambientais significativos (BRASIL, 2009). Nesse contexto, a A3P encontra-se estruturada em cinco eixos temáticos (BRASIL, 2009).

Uso racional dos recursos naturais e bens públicos: usar os recursos naturais e bens públicos de forma econômica e racional, evitando o seu desperdício e reduzindo custos de produção. Este eixo abrange o uso racional de água, energia e madeira, além da redução do consumo de copos plásticos, papel e outros materiais de expediente; 
Gestão adequada dos resíduos sólidos gerados: envolve a adoção da política dos $5 \mathrm{Rs}$. Incialmente, deve-se pensar em reduzir o consumo e combater o desperdício, para só então realizar a destinação adequada dos resíduos;

Qualidade de vida no ambiente de trabalho: objetiva facilitar e satisfazer as necessidades do funcionário ao desenvolver suas atividades na organização por meio de ações para o desenvolvimento pessoal e profissional. Este eixo implica no uso e desenvolvimento de capacidades, na integração social e interna, no respeito à legislação e em condições de segurança e saúde no trabalho;

Sensibilização e capacitação dos servidores: a sensibilização objetiva desenvolver e consolidar uma consciência cidadã da responsabilidade socioambiental nos servidores. Já o processo de capacitação visa o desenvolvimento de competências institucionais e individuais; $\mathrm{e}$

Licitações sustentáveis: destinam-se à aquisição de bens e serviços sustentáveis, de modo que promovam a conservação ambiental e proporcionem uma melhor relação custo/benefício a médio ou longo prazo.

É importante ressaltar que ações de conscientização e sensibilização ambiental são indispensáveis à efetivação da A3P. A educação ambiental é uma ferramenta essencial à implantação e efetivação do programa, uma vez que dá suporte a todos os eixos temáticos do programa, através da geração de mudanças de hábitos - por parte dos gestores e servidores públicos - e da cultura institucional (FERREIRA, 2012).

\section{O processo de implantação da A3P em órgãos públicos}

Qualquer entidade pública pode implantar a A3P. A formalização da adesão ao programa se dá mediante assinatura do Termo de Adesão e Plano de Trabalho. Para formalizar a adesão, o órgão precisa (BRASIL, 2009): criar e regulamentar a Comissão Gestora da A3P; realizar um diagnóstico ambiental; desenvolver projetos e atividades; mobilizar e sensibilizar; e avaliar e monitorar. Para implantar a A3P é imprescindível criar uma Comissão Gestora, que tem como objetivo sensibilizar os gestores públicos a respeito da relevância da implantação do programa. Após a formação da Comissão, a primeira ação a ser realizada é levantar dados sobre a situação socioambiental da instituição.

O diagnóstico tem como objetivo direcionar as melhores ações a serem desenvolvidas na instituição, a partir de levantamentos e pesquisas que permitam coletar informações pertinentes aos eixos da A3P. Por meio do diagnóstico, pode-se identificar potencialidades e pontos críticos, avaliar possíveis desperdícios em relação ao consumo, impactos ambientais gerados, além de mapear os gastos da instituição (BRASIL, 2009).

Tomando por base o diagnóstico, o próximo passo é elaborar um Programa de Gestão Socioambiental, o qual deve estabelecer os objetivos, as ações que serão implementadas e as metas. Para a efetiva implantação da A3P, é essencial o trabalho de mobilização e sensibilização, como campanhas, cursos, entre outros. Por fim, o monitoramento contínuo e a avaliação periódica asseguram que sejam identificados os pontos críticos, as melhorias necessárias e os procedimentos exitosos. Nesta etapa, são mensurados os avanços alcançados e, se for o caso, as atividades são replanejadas.

Acerca do processo de implantação da A3P no âmbito dos órgãos públicos, existem duas Portarias do MMA que tratam da A3P são: a Portaria MMA n221, de 10 de setembro de 2004, que institui a estrutura de gestão da A3P; e a Portaria MMA no42, de 21 de fevereiro de 2005, que designa a composição da Comissão Gestora da A3P. 
Especificamente com relação às normas que abordam a implantação da A3P no MMA, destacam-se: 1) a Portaria MMA no 61, de 15 maio de 2008, que estabelece práticas de sustentabilidade ambiental nas compras públicas sustentáveis; e, 2) a Portaria MMA no 217, de 30 de julho de 2008, que institui o Comitê de Implementação da A3P no Ministério.

\section{Principais políticas públicas e legislações federais que fundamentam a A3P}

Atualmente, o principal desafio da A3P é promover a responsabilidade socioambiental como política governamental, contribuindo para integrar a agenda de crescimento econômico, concomitantemente, aos aspectos sociais e ambientais do processo de desenvolvimento. Deste modo, enquanto programa do Governo Federal, a A3P está fundamentada em importantes legislações e políticas públicas federais, as quais servem de embasamento legal para os seus princípios e diretrizes. Entre as principais, destacam-se: a Constituição Federal de 1988, as políticas nacionais de meio ambiente, de resíduos sólidos, de recursos hídricos e energéticos, de educação ambiental e mudanças climáticas, a Agenda 21, o Estatuto das Cidades, o Sistema Nacional de Unidades de Conservação, a Lei de Crimes Ambientais, além de decretos, instruções normativas e portarias.

\section{Política Nacional do Meio Ambiente}

No Brasil, a Lei no 6.938, de 31 de agosto de 1981 é considerada o marco inicial das ações voltadas à conservação ambiental e à inserção da temática ambiental nas atividades de diversos setores da sociedade. Ela dispõe sobre a Política Nacional do Meio Ambiente (PNMA), seus fins e mecanismos de formulação e aplicação. Segundo Kishi (2007), a PNMA estrutura as diretrizes, as regras e os princípios, os instrumentos de proteção, as políticas públicas ambientais, as estratégias e ações referentes à preservação da natureza, tendo como princípio fundamental a garantia de um ambiente equilibrado.

Os principais instrumentos da PNMA são (BRASIL, 1981): o estabelecimento de padrões de qualidade ambiental; o zoneamento ambiental; a avaliação de impactos ambientais; o licenciamento e a revisão de atividades efetiva ou potencialmente poluidoras; a criação de espaços territoriais especialmente protegidos pelo Poder Público; o sistema nacional de informações sobre o meio ambiente, entre outros. A PNMA tem sua relevância associada à instituição de um importante e moderno mecanismo de proteção ambiental, que é o estudo prévio de impacto ambiental (EIA) e seu respectivo relatório (RIMA). Outro legado desta política diz respeito ao estabelecimento de definições legais sobre vários assuntos, como: meio ambiente, poluição, poluidor, degradação ambiental e recursos ambientais.

\section{Constituição Federal}

A Constituição Federal de 1988, pela primeira vez na história legislativa do Brasil, passou a destinar um capítulo específico para tratar do meio ambiente. Até então, as Cartas Magnas abordavam a questão ambiental de forma fragmentada e setorizada, abordando as questões ambientais através de normas que passavam a tratar de florestas, caça, pesca, energia, águas, entre outros (CAPELLI, 2002). 
Atualmente, 0 art. 225 da Constituição brasileira consagra que "todos têm direito ao meio ambiente ecologicamente equilibrado, bem de uso comum do povo e essencial à sadia qualidade de vida" (BRASIL, 1988). O aparato legal ainda prevê que é dever tanto do Poder Público quanto da sociedade defender e preservar o meio ambiente para as atuais e futuras gerações.

Ainda que não esteja explicitado, observa-se que a ideia central do conceito de desenvolvimento sustentável apresentado pela Comissão Brundtland - desenvolvimento que atende às necessidades do presente sem comprometer a possibilidade de as gerações futuras também atenderem as suas necessidades (CMMAD, 1991) - está contida na Constituição de 1988.

Ao trazer como responsabilidade do Poder Público e da sociedade a defesa e preservação do meio ambiente, a Constituição pressupõe a implementação de políticas públicas, concebidas em conjunto com a comunidade em geral, para cumprir com esse dever que se estende às presentes e às futuras gerações (LEME, 2010). $O$ art. 170 da Constituição Federal estabelece que este dever do Poder Público deve assegurar uma existência digna a todos os indivíduos, em conformidade com os princípios da justiça social e a defesa do meio ambiente (BRASIL, 1988). A Constituição de 1988, portanto, representa um marco na legislação ambiental brasileira, uma vez que passa a admitir que os problemas socioambientais que afligem a sociedade demandam ações e respostas da coletividade e do Estado, no sentido de garantir um desenvolvimento sustentável.

A ordem econômica, fundada na valorização do trabalho humano e na livre iniciativa, tem por fim assegurar a todos existência digna, conforme os ditames da justiça social, observados os seguintes princípios: (...)

VI: defesa do meio ambiente, inclusive mediante tratamento diferenciado conforme o impacto ambiental dos produtos e serviços e de seus processos de elaboração e prestação.

\section{Lei de Licitações e Contratos}

A Lei no 8.666, de 21 de junho de 1993 é uma das legislações básicas sobre licitações e contratos para a Administração Pública. Em 2010, esta lei sofreu uma modificação no seu art. 3ำ o qual passou a trazer a promoção do desenvolvimento sustentável como um dos princípios das licitações públicas (BRASIL, 1993). Com base neste artigo, uma vez demonstrado nos autos dos processos licitatórios que as aquisições de bens e serviços realizadas pelos gestores promovem o desenvolvimento sustentável, estarão legalmente justificadas as suas escolhas. Porém, o conceito de desenvolvimento sustentável, neste contexto, pode gerar incerteza e até mesmo algum tipo de insegurança jurídica, uma vez que na Lei não estão especificados parâmetros de definição de produtos melhores para o meio ambiente.

A licitação destina-se a garantir a observância do princípio constitucional da isonomia, a seleção da proposta mais vantajosa para a administração e a promoção do desenvolvimento nacional sustentável e será processada e julgada em estrita conformidade com os princípios básicos da legalidade, da impessoalidade, da moralidade, da igualdade, da publicidade, da probidade administrativa, da vinculação ao instrumento convocatório, do julgamento objetivo e dos que lhes são correlatos (BRASIL, 1993).

Sobre isto, Ferreira (2012) preconiza que duas leis dão o norte e os parâmetros para o que sejam produtos sustentáveis: a de Mudança Climática e a de Resíduo Sólido. De acordo com os elementos apresentados em tais legislações, os produtos que se enquadram como melhores para o meio ambiente são 
os que propiciam maior economia de energia, água e outros recursos naturais, redução de gases de efeito estufa e de resíduos, e produtos reciclados e recicláveis.

Entre os instrumentos legais que dispõem sobre a temática socioambiental e a aquisição de produtos sustentáveis no âmbito das entidades da Administração Pública Federal, encontra-se o Decreto no 2.783/08, que dispõe sobre proibição de aquisição de produtos ou equipamentos que contenham ou façam uso das substâncias que destroem a camada de ozônio.

Do ponto de vista infralegal, a Instrução Normativa no 01, de 19 de janeiro de 2010, da Secretaria de Logística e Tecnologia da Informação do Ministério do Planejamento, Orçamento e Gestão (SLTI/MPOG), dispõe sobre critérios de sustentabilidade ambiental aplicados na aquisição de bens, contratação de serviços ou obras públicas pela Administração Pública. Ela trata, entre outros assuntos, da necessidade de se usar racionalmente os recursos naturais, especialmente água e energia, durante todo o ciclo de produção.

Outro ato normativo do Governo Federal que dispõe sobre a temática socioambiental é a Instrução Normativa no 10, de 12 de novembro de 2012. Ela estabelece as regras para elaboração dos Planos de Gestão de Logística Sustentável (PLS) pela Administração Pública Federal. Os PLS são ferramentas de planejamento que permitem aos órgãos estabelecer práticas de sustentabilidade e racionalização de gastos e processos na Administração Pública.

\section{Política Nacional de Recursos Hídricos}

A Política Nacional de Recursos Hídricos (PNRH) foi instituída pela Lei no 9.433, de 8 de janeiro de 1997 - Lei das Águas - e apresenta como principais fundamentos: a água é um bem de domínio público, considerada um recurso natural limitado e dotado de valor econômico; em casos de escassez, ela deve ser usada prioritariamente para o consumo humano e a dessedentação de animais; e, a gestão dos recursos hídricos deve ser descentralizada e contar com a participação do poder público, dos usuários e das comunidades (BRASIL, 1997). Os objetivos da PNRH estão associados à promoção da utilização sustentável dos recursos hídricos e à prevenção contra eventos hidrológicos prejudiciais (BRASIL, 1997):

I - assegurar à atual e às futuras gerações a necessária disponibilidade de água, em padrões de qualidade adequados aos respectivos usos;

II - a utilização racional e integrada dos recursos hídricos, incluindo o transporte aquaviário, com vistas ao desenvolvimento sustentável,

III - a prevenção e a defesa contra eventos hidrológicos críticos de origem natural ou decorrentes do uso inadequado dos recursos naturais.

Como instrumentos da PNRH, foram definidos: os Planos de Recursos Hídricos; o enquadramento dos corpos de água em classes, de acordo com os usos preponderantes da água; a outorga dos direitos de uso de recursos hídricos e a cobrança pelo seu uso; a compensação a municípios; e, o Sistema de Informações sobre Recursos Hídricos.

Oliveira (2011) afirma que a PNRH se tornou um marco para o Brasil, pois, apesar de o País possuir cerca de $12 \%$ da água doce disponível no mundo, ainda apresenta sérios problemas relacionados à disponibilidade de água, em virtude da distribuição e da demanda heterogênea do recurso em seu território. Além disso, antes da instituição da PNRH, o uso da água era regido por várias normas e códigos, os quais 
muitas vezes apresentavam visões conflitantes e eram executados por uma estrutura institucional ineficaz (MILARÉ, 2007).

\section{Política Nacional de Educação Ambiental}

A Lei no 9.795, de 27 de abril de 1999 institui a educação ambiental e define a Política Nacional de Educação Ambiental (PNEA). Segundo o dispositivo legal, em seu art. 1o, a educação ambiental é definida como sendo os processos através dos quais o indivíduo e a coletividade constroem valores sociais, conhecimentos, habilidades, atitudes e competências voltados à conservação ambiental (BRASIL, 1999).

Alguns dos princípios básicos da educação ambiental são: o enfoque humanista, holístico, democrático e participativo; a concepção do meio ambiente sob a perspectiva da sustentabilidade; o pluralismo de ideias e concepções pedagógicas; a vinculação entre a ética, a educação, o trabalho e as práticas sociais; a abordagem articulada das questões ambientais locais, regionais, nacionais e globais; e, o respeito à pluralidade e à diversidade individual e cultural (BRASIL, 1999).

Observa-se que a educação ambiental, da forma como é tratada na PNEA, abrange não apenas aspectos individuais do processo educativo, mas também os sociais. Assim, o processo de educação ambiental é visto como uma responsabilidade social de todos, devendo ser um componente essencial da educação nacional.

\section{Lei de Crimes Ambientais}

A Lei no 9.605, de 12 de fevereiro de 1998 (BRASIL, 1998), dispõe sobre as sanções penais e administrativas oriundas de condutas e atividades lesivas ao meio ambiente. A Lei de Crimes Ambientais, como é conhecida, passa a tratar das penas e infrações, de forma centralizada, visto que até então a proteção ambiental era um grande desafio, pois as leis eram dispersas e difíceis de serem aplicadas. De acordo com a legislação, os crimes ambientais podem ser classificados em: crimes contra a fauna; crimes contra a flora; poluição e outros crimes ambientais; crimes contra o ordenamento urbano e o patrimônio cultural; crimes contra a Administração Ambiental; e, infrações administrativas (BRASIL, 1998). Diante de um crime ambiental, o instrumento jurídico que protege o meio ambiente é a ação civil pública, regulamentada pela Lei no $7.347 / 85$.

A Lei de Crimes Ambientais estabelece que uma pessoa jurídica infratora não pode ter a sua liberdade restringida da mesma forma que uma pessoa comum. Então, ela pode ter: a suspensão parcial ou total das atividades; a interdição temporária de estabelecimento, obra ou atividade; a proibição de contratar com o Poder Público; a prestação de serviços à comunidade; a execução de obras de recuperação de áreas degradadas; e, contribuições a entidades ambientais ou culturais públicas (BRASIL, 1998).

\section{Sistema Nacional de Unidades de Conservação}

O Sistema Nacional de Unidades de Conservação (SNUC), instituído pela Lei no 9.985, de 18 de julho de 2000, tem como objetivo garantir a biodiversidade, a variedade dos recursos genéticos e a integridade 
dos processos ambientais. A lei estabelece critérios e normas para a criação, implantação e gestão das unidades de conservação, cuja gestão deve ser pautada pela promoção do desenvolvimento sustentável (BRASIL, 2000). O SNUC, segundo Sousa et al. (2011), representa avanços na política de expansão e gestão de áreas protegidas, oferece uma visão integrada do conjunto de unidades de conservação no território brasileiro e enfatiza a relação entre o Estado, os cidadãos e o meio ambiente, à medida que amplia a participação da sociedade na gestão do Sistema.

\section{Política Urbana e Política Nacional de Conservação e Uso Racional de Energia}

O Estatuto das Cidades - Lei № 10.257, de 10 de julho de 2001 - regulamenta o capítulo da Constituição Federal que trata da política urbana, assim como estabelece as suas diretrizes gerais. Também institui normas que regulam o uso da propriedade urbana em benefício do bem comum, da segurança, do bem estar dos cidadãos e do equilíbrio ambiental.

A política urbana tem por objetivo ordenar o pleno desenvolvimento das funções sociais da cidade e da propriedade urbana, através: da garantia do direito a cidades sustentáveis; da gestão democrática; da cooperação entre os diversos setores da sociedade; do planejamento e desenvolvimento das cidades; da oferta de equipamentos urbanos e serviços públicos adequados às necessidades da população e às características locais; e, da ordenação e controle do uso do solo (BRASIL, 2001).

A Política Nacional de Conservação e Uso Racional de Energia - Lei no 10.295, de 17 de outubro de 2001 - tem como objetivo alocar de modo eficiente os recursos energéticos e a preservação do meio ambiente, através do estabelecimento de níveis máximos de consumo de energia, ou mínimos de eficiência energética, de máquinas e aparelhos fabricados ou comercializados no País (BRASIL, 2001). Sobre esse tema, é importante destacar que existe, no âmbito da Administração Pública Federal, o Decreto no 4.131/02, o qual dispõe sobre medidas emergenciais de redução do consumo de energia elétrica.

\section{Política Nacional de Mudanças Climáticas}

O Brasil é um país protagonista na instituição de políticas públicas de mudanças climáticas. A Política Nacional de Mudanças Climáticas (PNMC), instituída pela Lei no 12.187, de 29 de dezembro de 2009, estabelece que as medidas a serem adotadas para a sua execução devem partir do princípio de que todos têm o dever de atuar na redução dos impactos decorrentes da ação antrópica sobre o sistema climático, levando em consideração os princípios do desenvolvimento sustentável, os diferentes contextos socioambientais e as ações promovidas por entidades públicas e privadas. Entre os diversos instrumentos da PNMC, a lei preconiza, em seu art. 6으, inciso XII, o seguinte (BRASIL, 2009):

São instrumentos da Política Nacional Sobre Mudança do Clima: (...)

XII - as medidas existentes, ou a serem criadas, que estimulem o desenvolvimento de processos e tecnologias, que contribuam para a redução de emissões e remoções de gases de efeito estufa, bem como para a adaptação, dentre as quais o estabelecimento de critérios de preferência nas licitações e concorrências públicas, compreendidas aí as parcerias público-privadas e a autorização, permissão, outorga e concessão para exploração de serviços públicos e recursos naturais, para as propostas que propiciem maior economia 
de energia, água e outros recursos naturais e redução da emissão de gases de efeito estufa e de resíduos.

A respeito deste instrumento, Ferreira (2012) destaca que ao invés de a PNMC trabalhar com o conceito vago de "produtos sustentáveis", traz um nível de detalhamento necessário à sua compreensão: aqueles que proporcionam uma maior economia de energia, água e outros recursos naturais, além da redução de emissão de gases de efeito estufa e de resíduos. As consequências decorrentes do processo de mudanças climáticas e sua relação com a produção dos gases estufa pela atividade humana demonstram que as emissões destes gases durante o ciclo de produção de bens e serviços precisam ser consideradas para se chegar ao uso racional dos recursos naturais (BLIACHERIS, 2012).

\section{Política Nacional de Resíduos Sólidos}

A Lei 12.305, de 2 de agosto de 2010 institui a Política Nacional de Resíduos Sólidos (PNRS) e propõe a prática de hábitos de consumo sustentáveis, à medida que defende a prevenção e a redução na geração de resíduos, bem como a utilização de instrumentos que propiciam o aumento da reciclagem, a reutilização de resíduos e a destinação final ambientalmente adequada dos rejeitos (BRASIL, 2015).

A PNRS é parte integrante da PNMA e está articulada com a Política Nacional de Educação Ambiental (PNEA). Entre os principais princípios que norteiam a PNRS, destacam-se (BRASIL, 2010): a prevenção e precaução; o poluidor-pagador e protetor-recebedor; a visão sistêmica da gestão de resíduos sólidos; o desenvolvimento sustentável; a ecoeficiência; a cooperação entre o poder público, as empresas e a sociedade; a responsabilidade compartilhada pelo ciclo de vida dos produtos; o reconhecimento do resíduo sólido como um bem econômico e de valor social; o respeito às diversidades locais e regionais; o direito da sociedade à informação e ao controle social; e, a razoabilidade e proporcionalidade.

Ao tratar das diretrizes aplicáveis aos resíduos sólidos, a PNRS, em seu art. 9ํ, estabelece que a gestão e o gerenciamento dos resíduos devem ser realizados levando-se em consideração a seguinte ordem: não geração, redução, reutilização, reciclagem, tratamento dos resíduos sólidos e disposição final ambientalmente adequada dos rejeitos (BRASIL, 2010). Observa-se uma estreita ligação entre tais diretrizes e o que está proposto na política dos 5R's.

A PNRS, segundo Jacobi et al. (2011), fortalece os princípios da gestão integrada e sustentável de resíduos, recomenda medidas de incentivo à formação de consórcios públicos para a gestão regionalizada, propõe a responsabilidade compartilhada pelo ciclo de vida dos produtos e a logística reversa, defende metas de redução de disposição final de resíduos em aterros sanitários e ressalta a importância do papel das organizações de catadores para o sistema de coleta seletiva. Acerca da temática gestão de resíduos sólidos e, em consonância com a PNRS, cabe destacar a existência de dois Decretos, no âmbito do Governo Federal: o Decreto no7.404/10, o qual estabelece normas para execução da PNRS; e o Decreto n⒌940/06, que institui a separação dos resíduos recicláveis descartados pelos órgãos e entidades da Administração Pública Federal, na fonte geradora, e a sua destinação às associações e cooperativas dos catadores de materiais recicláveis. 
Ações relacionadas aos eixos temáticos da A3P e sua relação com os objetivos centrais das políticas públicas e legislações que a fundamentam

Ao estimular a inserção de atitudes sustentáveis na rotina dos órgãos públicos brasileiros, nas três esferas de poder - Executivo, Legislativo e Judiciário - , a A3P constitui um importante instrumento de aproximação dos cidadãos das mais diversas políticas públicas socioambientais federais promovidas e efetivadas pelo Estado.

Numa perspectiva prática, as experiências de adesão de órgãos públicos ao programa A3P demonstram como a maioria das ações relativas a cada um dos seus eixos temáticos encontram fundamentos nas políticas socioambientais existentes no Brasil (FREITAS et al., 2011; RÊGO et al., 2011; LUIZ et al., 2013 ; SANTANA et al., 2014; KRUGER et al., 2011; SOUZA et al., 2015; VIEGAS et al., 2015). Assim, a partir da implantação da A3P em um órgão público, em especial das ações relacionadas a cada um dos eixos temáticos da Agenda, observa-se a coadunação que existe entre as ações decorrentes da implantação do programa e os objetivos das políticas públicas e legislações que a fundamentam.

\section{Uso racional dos recursos naturais e bens públicos}

De acordo com BRASIL (2009), a economia brasileira é caracteriza por um elevado nível de desperdício de recursos naturais, o que pode levar à sua escassez. Diante deste cenário, a A3P, através do eixo temático 'uso racional dos recursos naturais e bens públicos', incentiva a adoção de boas práticas de economia e eficiência no uso dos principais recursos utilizados pela Administração Pública, como a madeira, o papel, a água e a energia. No Quadro 1, observam-se algumas ações que podem ser implantadas visando a utilização racional dos recursos naturais e o combate ao desperdício - primeiro eixo temático da $\mathrm{A3P}$ - , e suas contribuições ao cumprimento das legislações vigentes e à efetivação de políticas públicas socioambientais.

Quadro 1: Ações relacionadas ao primeiro eixo temático da A3P e sua relação com os objetivos centrais das políticas públicas e legislações que a fundamentam.

\begin{tabular}{|c|c|}
\hline \multicolumn{2}{|c|}{ Eixo temático - uso racional dos recursos naturais e bens públicos } \\
\hline Ações sugeridas & Relações \\
\hline $\begin{array}{l}\text { - Analisar e comparar os gastos e o consumo de madeira, água, } \\
\text { energia e materiais de expediente; } \\
\text { - Substituir ou reduzir o uso do papel, através de tecnologias de } \\
\text { desmaterialização de processos e documentos; } \\
\text { - Reaproveitar papéis tornados inúteis; } \\
\text { - Utilizar papéis recicláveis; } \\
\text { - Gerenciar as instalações, adotar equipamentos } \\
\text { tecnologicamente mais eficientes e avançados, alterar os } \\
\text { hábitos dos usuários, assegurando uma eficiência energética; } \\
\text { - Usar aparelhos economizadores de água; } \\
\text { - Instalar sistema de reaproveitamento de águas pluviais e } \\
\text { sistema de reuso das águas cinzas; } \\
\text { - Comunicar os responsáveis sobre vazamentos em torneiras, } \\
\text { filtros e descargas; } \\
\text { - Sugerir a colocação de adesivos com mensagens educativas } \\
\text { sobre a necessidade do bom uso da água e da energia no } \\
\text { ambiente de trabalho. }\end{array}$ & $\begin{array}{l}\text { - Favorece a efetivação de políticas e estratégias de estímulo a } \\
\text { mudanças nos padrões insustentáveis de consumo (capítulo } 4 \\
\text { da Agenda 21; Lei no } 12.187 / 09 \text { - Política Nacional sobre } \\
\text { Mudança do Clima; Lei no 12.305/10 - Política Nacional de } \\
\text { Resíduos Sólidos; Instrução normativa SLTI/MPOG no 01/2010); } \\
\text { - Estimula o uso racional da água (Lei no 9.433/97 - Política } \\
\text { Nacional de Recursos Hídricos) e da energia (Lei no } 10.295 / 01 \text { - } \\
\text { Política Nacional de Conservação e Uso racional de Energia); } \\
\text { - Contribui ao alcance dos objetivos da política dos } 5 \text { Rs: } \\
\text { repensar, recusar, reduzir, reutilizar e reciclar; } \\
\text { - Contribui para o cumprimento da Lei no 9.795/99 - Política } \\
\text { Nacional de Educação Ambiental, através do processo de } \\
\text { conscientização e sensibilização dos indivíduos e da } \\
\text { coletividade; } \\
\text { - Proporciona a conservação dos recursos naturais e a proteção } \\
\text { ambiental (Lei no } 6.938 / 81 \text { - Política Nacional do Meio } \\
\text { Ambiente); } \\
\text { - Atende ao princípio da eficiência, estabelecido no art. } 37 \text { da } \\
\text { Constituição Federal. }\end{array}$ \\
\hline
\end{tabular}

Fonte: BRASIL (2009). 
A adoção de ações voltadas ao uso racional dos recursos naturais e bens públicos constitui um importante meio para a efetivação de diversas políticas públicas e legislações no âmbito federal. Além de favorecer a efetivação de políticas públicas integradas relacionadas ao meio ambiente, aos resíduos sólidos, às mudanças climáticas e à educação ambiental, tais ações estão em harmonia com a Agenda 21 e com a Constituição Federal.

\section{Gestão adequada dos resíduos gerados}

A gestão inadequada de resíduos sólidos é apontada como um dos principais problemas ambientais que afetam a sociedade. Associada ao consumo desenfreado, ela cria enormes riscos à saúde pública e à qualidade de vida da população. Quanto à saúde, o gerenciamento incorreto dos resíduos tem enorme potencial para contaminar solos e águas, favorecendo a proliferação de vetores (JACOBI et al., 2011). Então, diante da importância que a questão dos resíduos assume na atualidade, a A3P tem como segundo eixo temático a gestão adequada dos resíduos gerados nos órgãos públicos. As iniciativas relacionadas a este eixo abrangem os princípios dos 5Rs: repensar, recusar, reduzir, reutilizar e reciclar.

No quadro 2, pode-se observar sugestões de ações que podem ser adotadas visando a correta gestão dos resíduos - segundo eixo temático da A3P. Tais ações, além de possibilitarem o atendimento às legislações vigentes, estão profundamente relacionadas com os objetivos centrais das políticas públicas e legislações socioambientais que a fundamentam a A3P.

Quadro 2: Ações relacionadas ao segundo eixo temático da A3P e sua relação com os objetivos centrais das políticas públicas e legislações que a fundamentam.

\begin{tabular}{|c|c|}
\hline \multicolumn{2}{|c|}{ Eixo temático - gestão adequada dos resíduos gerados } \\
\hline Ações sugeridas & Relações \\
\hline $\begin{array}{l}\text { - Reduzir o consumo, o desperdício e os gastos } \\
\text { excessivos com materiais de expediente, de } \\
\text { limpeza, móveis, equipamentos, entre outros; } \\
\text { - Reaproveitar tudo o que estiver em bom } \\
\text { estado; } \\
\text { - Evitar que mais matérias-primas sejam } \\
\text { extraídas da natureza, reciclando materiais, } \\
\text { como vidro, alumínio, papel, etc. } \\
\text { - Repensar os valores e práticas de consumo; } \\
\text { - Recusar consumir produtos que geram } \\
\text { impactos ambientais negativos. } \\
\text { - Implementar a coleta seletiva de resíduos; } \\
\text { - Destinar adequadamente os resíduos } \\
\text { perigosos. }\end{array}$ & $\begin{array}{l}\text { - Favorece o manejo adequado dos resíduos sólidos, melhorias em termos de } \\
\text { saúde pública e proteção ao meio ambiente (Lei no } 12.305 / 10 \text { - Política Nacional } \\
\text { de Resíduos Sólidos; Lei no } 6.938 / 81 \text { - Política Nacional do Meio Ambiente; } \\
\text { Decreto no 5.940/06; Decreto no } 7.404 / 10 \text { ); } \\
\text { - Contribui para o alcance dos objetivos propostos pela Lei no 9.795/99 - Política } \\
\text { Nacional de Educação Ambiental. } \\
\text { - Estimula a adoção da política dos } 5 \text { Rs e de estratégias contidas na Agenda 21; } \\
\text { - Promove ações visando o uso racional dos recursos naturais e bens públicos e, } \\
\text { por conseguinte, as políticas públicas que dispõem sobre o tema. }\end{array}$ \\
\hline
\end{tabular}

Fonte: BRASIL (2009).

A implantação de ações relacionadas ao segundo eixo da A3P possui um papel fundamental para a efetivação da PNRS e, de modo transversal, para o alcance dos objetivos propostos na PNMA, na PNEA e em outras legislações que dispõem sobre a temática. Observa-se que este eixo temático da A3P está profundamente relacionado ao eixo que trata do uso racional dos recursos naturais e bens públicos, uma vez que o uso racional dos recursos implica em resultados positivos na gestão de resíduos, sobretudo na redução na quantidade de resíduos gerada. 


\section{Qualidade de vida no ambiente de trabalho}

Pensar sobre o terceiro eixo temático da A3P — qualidade de vida no ambiente de trabalho — exige uma profunda reflexão e um conhecimento transversal, o qual deve incluir todas as práticas de políticas públicas, embasadas na ética e na estética da vida (ROCHA, 2012). O Quadro 3 apresenta possíveis ações de serem implantadas a partir da A3P e como elas se relacionam com os objetivos das políticas públicas e legislações que a fundamentam.

Quadro 3: Ações relacionadas ao terceiro eixo temático da A3P e sua relação com os objetivos centrais das políticas públicas e legislações que a fundamentam.

\begin{tabular}{|c|c|}
\hline \multicolumn{2}{|c|}{ Eixo temático - qualidade de vida no ambiente de trabalho } \\
\hline Ações sugeridas & Relações \\
\hline $\begin{array}{l}\text { - Implantar programas de qualidade de vida, } \\
\text { saúde e segurança no trabalho; } \\
\text { - Instituir comissão de prevenção de acidentes } \\
\text { de trabalho; } \\
\text { - Instituir brigadas de incêndio nos locais de } \\
\text { trabalho; } \\
\text { - Realizar manutenção ou substituição de } \\
\text { aparelhos que provocam ruídos; } \\
\text { - Promover atividades de integração no } \\
\text { ambiente de trabalho e qualidade de vida, } \\
\text { como ginástica laboral, oficinas de talento, } \\
\text { etc.; } \\
\text { - Avaliar a satisfação dos servidores; } \\
\text { - Promover iniciativas que favoreçam o uso e } \\
\text { desenvolvimento de capacidades. }\end{array}$ & $\begin{array}{l}\text { - Estimula a preservação, melhoria e recuperação da qualidade ambiental } \\
\text { propícia à vida e à dignidade humana, em consonância com a Lei no } 6.938 / 81 \text { - } \\
\text { Política Nacional do Meio Ambiente; } \\
\text { - Ao desenvolver ações voltadas ao benefício do bem comum, da segurança, do } \\
\text { bem estar dos cidadãos e do equilíbrio ambiental, está sendo observado o que } \\
\text { dispõe a Lei no } 10.257 / 01 \text {, que trata da política urbana. } \\
\text { - As ações de qualidade de vida no trabalho coadunam com o que estabelece o } \\
\text { art. } 225 \text { da Constituição Federal, em que "todos têm direito ao meio ambiente } \\
\text { ecologicamente equilibrado, bem de uso comum do povo e essencial à sadia } \\
\text { qualidade de vida". }\end{array}$ \\
\hline
\end{tabular}

Fonte: BRASIL (2009).

Além de exigir um conhecimento proveniente de diversas áreas, constata-se que a qualidade de vida no trabalho inclui diferentes práticas que encontram subsídios legais nas políticas públicas, desde aquelas que tratam da preservação e proteção ambiental - condição necessária à qualidade de vida humana - até as que abordam as temáticas da segurança, bem-estar social e saúde.

\section{Sensibilização e capacitação dos servidores}

As ações que promovem a sensibilização e a capacitação de servidores públicos fazem do quarto eixo da A3P um importante referencial de práticas que contribuem para a efetivação da PNEA e da PNMA, além de outras políticas públicas que abrangem, por exemplo, o uso racional dos recursos hídricos e energéticos e a adequada gestão dos resíduos. As ações pertinentes a este eixo da A3P, portanto, permeiam os demais eixos do programa e favorecem a execução de políticas públicas que se integram, a partir de seus objetivos.

Muitas pessoas não têm consciência dos impactos sobre o meio ambiente, decorrentes de suas atividades diárias. Devido à problemática socioambiental, a A3P, através do seu quarto eixo temático sensibilização e capacitação - apoia iniciativas de promoção da conscientização e sensibilização dos servidores públicos, tendo por finalidade a criação de uma nova cultura institucional de sustentabilidade (BRASIL, 2009). O Quadro 4 expõe algumas das ações que podem ser realizadas no tocante ao eixo temático da A3P "sensibilização e capacitação dos servidores", assim como e sua relação com os objetivos das políticas públicas e legislações que fundamentam o Programa. 
Quadro 4: Ações relacionadas ao quarto eixo temático da A3P e sua relação com os objetivos centrais das políticas públicas e legislações que a fundamentam.

\begin{tabular}{|c|c|}
\hline \multicolumn{2}{|c|}{ Eixo temático - sensibilização e capacitação dos servidores } \\
\hline Ações sugeridas & Relações \\
\hline $\begin{array}{l}\text { - Realizar campanhas que busquem } \\
\text { chamar a atenção dos indivíduos para } \\
\text { temas socioambientais relevantes; } \\
\text { - Criar formas interessantes de } \\
\text { envolvimento das pessoas em uma ação } \\
\text { voltada à coletividade e à melhoria da } \\
\text { qualidade de vida; } \\
\text { - Orientar para a redução no consumo e } \\
\text { para possibilidades de reaproveitamento } \\
\text { de materiais; } \\
\text { - Incentivar o protagonismo e a reflexão } \\
\text { crítica dos servidores sobre as questões } \\
\text { socioambientais; } \\
\text { - Promover palestras, minicursos, fóruns } \\
\text { que promovam a sensibilização dos } \\
\text { servidores; } \\
\text { - Elaborar um plano de capacitação para } \\
\text { os servidores públicos do órgão; } \\
\text { - Produzir informativos referentes a } \\
\text { temas diversos relacionados às temáticas } \\
\text { socioambientais. }\end{array}$ & $\begin{array}{l}\text { - Cumprimento da Lei no 9.795/99 - Política Nacional de Educação Ambiental, à } \\
\text { medida que contribui para o processo de construção de conhecimentos, habilidades, } \\
\text { atitudes e competências voltadas à conservação do meio ambiente; } \\
\text { - Ações voltadas à conservação ambiental contribuem para o cumprimento da Lei no } \\
\text { 6.938/81 - Política Nacional do Meio Ambiente; } \\
\text { - A realização de ações educativas relacionadas a temáticas específicas, como resíduos } \\
\text { sólidos, recursos hídricos, uso racional dos recursos naturais e bens públicos, favorece } \\
\text { a efetivação de outras políticas públicas, a exemplo da Política Resíduos Sólidos, da } \\
\text { Política de Recursos Hídricos e da Política que trata do uso racional de Energia. }\end{array}$ \\
\hline
\end{tabular}

Fonte: BRASIL (2009).

\section{Licitações sustentáveis}

O quinto eixo temático da A3P - licitações sustentáveis - envolve a promoção da responsabilidade socioambiental nas aquisições realizadas pela Administração Pública. Dados do BRASIL (2009) permitem estimar que as compras governamentais, no Brasil, movimentam cerca de $10 \%$ a $15 \%$ do Produto Interno Bruto (PIB) nacional. Este fato corrobora o poder de compra e contratação do Governo e, ao mesmo tempo, demonstra a necessidade de que nos processos de aquisições públicas esteja presente a inserção de critérios de sustentabilidade.

Quadro 5: Ações relacionadas ao quinto eixo temático da A3P e sua relação com os objetivos centrais das políticas públicas e legislações que a fundamentam.

\begin{tabular}{|c|c|}
\hline \multicolumn{2}{|c|}{ Eixo temático - licitações sustentáveis } \\
\hline Ações sugeridas & Relações \\
\hline $\begin{array}{l}\text { - Sempre que possível, adquirir bens e serviços } \\
\text { ambientalmente sustentáveis; } \\
\text { - Evitar compras desnecessárias; } \\
\text { - Evitar comprar produtos que contenham } \\
\text { substâncias que degradem a camada de ozônio; } \\
\text { - Inserir critérios ambientais nas licitações de } \\
\text { produtos, como veículos, alimentos orgânicos, } \\
\text { madeira certificada, lâmpadas fluorescentes, } \\
\text { mobiliário, etc.; } \\
\text { - Especificar o objeto a ser licitado com requisitos } \\
\text { voltados à conservação e preservação do meio } \\
\text { ambiente; } \\
\text { - Considerar no processo licitatório a qualidade e a } \\
\text { durabilidade dos produtos a serem adquiridos; } \\
\text { - Cumprir as legislações ambiental, trabalhista e de } \\
\text { direitos humanos e considerá-las nos processos de } \\
\text { aquisição; } \\
\text { - Priorizar, nas aquisições e contratações } \\
\text { governamentais, produtos reciclados e recicláveis. }\end{array}$ & $\begin{array}{l}\text { - Fortalece a efetivação das políticas públicas relacionadas às licitações } \\
\text { sustentáveis, como a Lei no } 8.666 / 93 \text {; a Lei no } 12.187 / 09 \text { - Política } \\
\text { Nacional sobre Mudança do Clima; e, a Lei no } 12.305 / 10 \text { - Política } \\
\text { Nacional de Resíduos Sólidos. } \\
\text { - Contribui para a conservação dos recursos naturais e a proteção } \\
\text { ambiental (Lei no } 6.938 / 81 \text { - Política Nacional do Meio Ambiente); } \\
\text { - Atende ao princípio da eficiência, estabelecido no art. } 37 \text { da } \\
\text { Constituição Federal; } \\
\text { - Cumpre o disposto na Instrução Normativa no } 01 \text {, de } 19 \text { de janeiro de } \\
2010 \text {, ao incentivar os processos de licitações sustentáveis; } \\
\text { - Auxilia no cumprimento da Política dos } 5 \text { Rs, com ênfase no princípio } \\
\text { "recusar" o consumo de produtos que agridem o meio ambiente. } \\
\text { - Atende às disposições do Decreto no } 2.783 / 08 \text {, que trata da proibição } \\
\text { de aquisição de produtos contribuam para a destruição da camada de } \\
\text { ozônio. }\end{array}$ \\
\hline
\end{tabular}

Fonte: BRASIL (2009). 
Diante da relevância que as licitações sustentáveis possuem no contexto socioeconômico, diversas iniciativas podem ser adotadas pelos órgãos públicos visando à aquisição de produtos e serviços sustentáveis. O quadro 5 apresenta algumas destas iniciativas e como elas estão associadas aos objetivos das políticas públicas e legislações que fundamentam a A3P.

À medida que são priorizados nos processos licitatórios produtos ambientalmente corretos, estão sendo efetivadas políticas públicas de preservação ao meio ambiente e cumpridas leis ambienteis que dispõem, entre outros assuntos, sobre as mudanças climáticas e os resíduos sólidos. As licitações sustentáveis, neste sentido, são apresentadas sob o aspecto das políticas públicas e se integram com outras legislações importantes, como a Constituição Federal, decretos e instruções normativas.

\section{CONCLUSÕES}

Este artigo teve por finalidade primordial analisar o programa A3P sob a perspectiva das políticas públicas socioambientais no âmbito federal brasileiro, abordando suas principais características e os desafios face à ampliação da usabilidade do programa nas entidades que compõem a esfera pública. Em um cenário marcado pelo agravamento dos problemas econômicos, sociais e ambientais, o programa A3P emerge como uma alternativa viável e, ao mesmo tempo, necessária, à disseminação de princípios norteadores de uma gestão multidimensional. Ademais, representa uma relevante ferramenta estratégica para a efetivação das diversas políticas públicas socioambientais.

Apesar de existir um vasto arcabouço jurídico - leis, decretos, portarias ministeriais e instruções normativas - para dar suporte às políticas públicas e aos programas relativos à responsabilidade socioambiental, em especial à $A 3 P$, uma verdadeira mudança de paradigma na Administração Pública brasileira se faz necessária, tendo em vista a reformulação dos padrões de produção e de consumo vigentes.

Neste contexto, o cumprimento do papel constitucionalmente estabelecido de defesa e preservação do meio ambiente pela Administração Pública passa pela adoção de critérios sustentáveis em suas atividades, através do desenvolvimento e aperfeiçoamento de políticas e programas em consonância com os princípios do desenvolvimento sustentável. Sob esta perspectiva, a A3P é um programa voltado à educação, à mudança de comportamento e à inserção de critérios de sustentabilidade nas atividades diárias da Administração Pública, cujos princípios estão em harmonia com importantes legislações que abordam as questões socioambientais.

Há que se ressaltar que o programa A3P contribui positivamente para a eficácia jurídica e social das normas e para o cumprimento de diferentes políticas públicas, as quais se integram em virtude de seus fundamentos e princípios. As ações realizadas a partir da implantação da A3P nos órgãos públicos encontramse relacionadas aos objetivos centrais das políticas públicas de meio ambiente, de resíduos sólidos, de uso racional dos recursos, de licitações sustentáveis e de educação ambiental - caracterizando a integração entre diversas políticas públicas e sua associação aos eixos temáticos da A3P.

A partir da exposição dos aspectos centrais da A3P, da descrição das principais legislações e políticas públicas federais que os fundamentam, e da demonstração de como as ações decorrentes da implantação 
do programa estão relacionadas com os objetivos das políticas públicas e legislações que fundamentam o programa, é possível constatar o significativo papel desempenhado pela A3P para o alcance dos objetivos precípuos de tais legislações e políticas.

Enquanto estratégia governamental para a promoção da responsabilidade socioambiental, a A3P dá suporte e oferece subsídios para que os órgãos e entidades adotem uma cultura de sustentabilidade e, consequentemente, efetivem as políticas públicas socioambientais no âmbito federal. Contudo, muitos são os desafios para a ampliação da usabilidade da estratégia tratada neste manuscrito. Devem ser considerados como entraves para este processo os aspectos político-ideológicos inerentes a cada administração pública federal, estadual ou municipal, os desalinhamentos dos modelos de gestão Brasil afora, inclusive as realidades e contextos dos locais, sobretudo no que diz respeito às prioridades elencadas em cada agenda.

Assim, cabe um estudo prático e comparativo voltado à avaliação da efetividade da A3P nas instâncias que a utilizam, que venha a abranger aspectos como: análise de resultados de gestão (com objetivo de verificar seus impactos positivos); análise do processo de aplicação da A3P (com o objetivo de estabelecer modelos); análise de aprendizagem das equipes estratégicas desenvolvedoras do instrumento nas diversas instâncias da gestão pública (com o objetivo de analisar criticamente o processo de quebra de paradigma a partir de sua implantação); e mapeamento e divulgação das melhores práticas proporcionadas pela A3P no âmbito do Brasil. Pelo fato de este artigo ter se tratado de um ensaio teórico, não foram abordadas práticas da A3P na gestão pública das cidades e estados brasileiros, cujas análises serviriam de base para avaliar a viabilidade da ferramenta, bem como sua praticabilidade.

Desta forma, as questões ora expostas podem servir de norte para pesquisas futuras, no intento de contribuírem para a difusão deste influente instrumento de gestão estratégica para o Setor Público, bem como de motivar, na prática, a mudança paradigmática voltada à Responsabilidade Socioambiental, considerando que seu escopo dominante está associado à promoção de reflexão acerca dos padrões modernos de produção e consumo, seja através de ações voltadas à utilização racional de recursos, bem como à gestão satisfatória, segundo preceitos do Desenvolvimento Sustentável, das diversas dimensões e atribuições inerentes à Gestão Pública Brasileira.

\section{REFERÊNCIAS}

ABREU, G. V.; FEITOSA, A. R.; MOTTA, L.. Experiência da Agenda Ambiental na Administração Pública: A3P no Ministério do Meio Ambiente. In: BLIACHERIS, M. W. FERREIRA, M. A. S. O.. Sustentabilidade na administração pública: valores e práticas de gestão socioambiental. Belo Horizonte: Fórum, 2012a. p.155-172.

BLIACHERIS, M.. Uso racional dos recursos na administração pública. In: BLIACHERIS, M. W.; FERREIRA, M. A. S. O.. Sustentabilidade na administração pública: valores e práticas de gestão socioambiental. Belo Horizonte: Fórum, 2012b. p.45-63.

BRASIL. Agenda 21: Conferência das Nações Unidas sobre Meio Ambiente e Desenvolvimento. 3 ed. Brasília: Senado Federal, 2001.
BRASIL. Constituição da República Federativa do Brasil. Brasília: Senado Federal, 1988

BRASIL. Lei n.10257 de 10 de julho de 2001. Regulamenta os arts. 182 e 183 da Constituição Federal, estabelece diretrizes gerais da política urbana e dá outras providências. Brasília: DOU, 2001.

BRASIL. Lei n.12187 de 29 de dezembro de 2009. Institui a Política Nacional sobre Mudança do Clima - PNMC e dá outras providências. Brasília: DOU, 2009.

BRASIL. Lei n.12305 de 2 de agosto de 2010. Institui a Política Nacional de Resíduos Sólidos; altera a Lei no 9.605, de 12 de fevereiro de 1998; e dá outras providências. Brasília: DOU, 2010. 
BRASIL. Lei $\mathbf{n . 6 9 3 8}$ de 31 de agosto de 1981. Dispõe sobre a Política Nacional do Meio Ambiente, seus fins e mecanismos de formulação e aplicação, e dá outras providências. Brasília: DOU, 1981.

BRASIL. Lei $\mathbf{n . 8 6 6 6}$ de 21 de junho de 1993. Regulamenta o art. 37, inciso XXI, da Constituição Federal, institui normas para licitações e contratos da Administração Pública e dá outras providências. Brasília: DOU, 1993.

BRASIL. Lei $\mathbf{n . 9 4 3 3}$ de 8 de janeiro de 1997. Institui a Política Nacional de Recursos Hídricos, cria o Sistema Nacional de Gerenciamento de Recursos Hídricos, regulamenta o inciso XIX do art. 21 da Constituição Federal, e altera o art. 10 da Lei no 8.001, de 13 de março de 1990, que modificou a Lei no 7.990, de 28 de dezembro de 1989. Brasília: DOU, 1997.

BRASIL. Lei $n .9605$ de 12 de fevereiro de 1998. Dispõe sobre as sanções penais e administrativas derivadas de condutas e atividades lesivas ao meio ambiente, e dá outras providências. Brasília: DOU, 1998.

BRASIL. Lei n.9795 de 27 de abril de 1999. Dispõe sobre a educação ambiental, institui a Política Nacional de Educação Ambiental e dá outras providências. Brasília: DOU, 1999.

BRASIL. Lei $\mathbf{n . 9 9 8 5}$ de 18 de julho de 2000. Regulamenta o art. 225, § 10, incisos I, II, III e VII da Constituição Federal, institui o Sistema Nacional de Unidades de Conservação da Natureza e dá outras providências. Brasília: DOU, 2000.

BRASIL. Ministério do Meio Ambiente. Agenda Ambiental na Administração Pública (A3P). 5 ed. Brasília: MMA, 2009.

BRASIL. Ministério do Meio Ambiente. Agenda Ambiental na Administração Pública. 4. ed. Brasília/DF: Ministério do Meio Ambiente, 2007.

CAPELLI, S.. Gestão ambiental no Brasil: sistema nacional de meio ambiente - do formal à realidade. In: Paola, M. E.. 10 Conferencia Internacional sobre Aplicación y Cumplimiento de la Normativa Ambiental em América Latina: material de trabajo y conclusiones. Buenos Aires: Fundación Ambiente y Recursos Naturales, 2002. p.49-57.

CAPRA, F.. O Ponto de mutação: a ciência, a sociedade e a cultura emergente. 25 ed. São Paulo: Cultrix, 2005.

CAVALCANTI, C.. Uma tentativa de caracterização da economia ecológica. Ambiente \& Sociedade, São Paulo, v.7, n.1, p.149-156, 2004.

CMMAD. Comissão Mundial sobre Meio Ambiente e Desenvolvimento. Nosso futuro comum. 2 ed. Rio de Janeiro: Editora da Fundação Getúlio Vargas, 1991.

COELHO, F. P.. É papel do Estado: mudar para promover a sustentabilidade. In: BLIACHERIS, M. W.; FERREIRA, M. A. S. O.. Sustentabilidade na administração pública: valores e práticas de gestão socioambiental. Belo Horizonte: Fórum, 2012. p.287-298.

DIAS, R.. Gestão ambiental: responsabilidade social e sustentabilidade. 2 ed. São Paulo: Atlas, 2011.

FERREIRA, M. A. S. O.. Apontamento sobre a gestão socioambiental na Administração Pública brasileira. In: BLIACHERIS, M. W.; FERREIRA, M. A. S. O.. Sustentabilidade na administração pública: valores e práticas de gestão socioambiental. Belo Horizonte: Fórum, 2012. p.21-43.

FREITAS, C. L.; BORGERT, A.; PFITSCHER, E. D.. Agenda ambiental na administração pública: uma análise da aderência de uma IFES as diretrizes propostas pela A3P. In: COLÓQUIO INTERNACIONAL SOBRE GESTÃO UNIVERSITÁRIA NA AMÉRICA DO SUL E II CONGRESSO INTERNACIONAL IGLU, 11. Anais. Florianópolis: UFSC, 2011.

JACOBI, P. R.; BESEN, G. R.. Gestão de resíduos sólidos em São Paulo: desafios da sustentabilidade. Estudos Avançados, São Paulo, v.71, n.25, p.135-158, 2011. DOI: http://doi.org/10.1590/S0103-40142011000100010

KISHI, S. A. S.. Política nacional do meio Ambiente e o desenvolvimento sustentado, a intervenção obrigatória do estado e o acesso ao bem ambiental. In: ROCHA, J. C. C.; HENRIQUES FILHO, T. H. P.; CAZETTA, U.. Política nacional do meio ambiente: 25 anos da Lei n. 6.938/81. Belo Horizonte: Del Rey, 2007. p.39-63.

KRUGER, S. D.; FREITAS, C. L.; PFITSCHER, E. D.; PETRI, S. M. Gestão ambiental em instituição de ensino superior: uma análise da aderência de uma instituição de ensino superior comunitária aos objetivos da agenda ambiental na administração pública (A3P). Revista GUAL, Florianópolis, v.4, n.3, p.44-62, 2011. DOI: http://doi.org/10.5007/19834535.2011v4n3p44

LEME, T. N.. Os municípios e a política nacional do meio ambiente. Planejamento e políticas públicas, Brasília, v.16, n.35, p.25-52, 2010.

LUIZ, L. C.; RAU, K.; FREITAS, C. L.; PFITSCHER, E. D.. Agenda Ambiental na Administração Pública (A3P) e práticas de sustentabilidade: estudo aplicado em um Instituto Federal de Educação, Ciência e Tecnologia. Administração Pública e Gestão Social, Viçosa, v.5, n.2, p.54-62, 2013.

MILARÉ, E.. Direito do ambiente: a gestão ambiental em foco: doutrina, jurisprudência, glossário. 5 ed. São Paulo: Editora Revista dos Tribunais, 2007.

OLIVEIRA, A. E. S.. Políticas socioambientais brasileiras e o aprendizado de uma nova ação. Desenvolvimento e Meio Ambiente, Paraná, n.23, p.133-148, 2011.

PECCATIELLO, A. F. O.. Políticas públicas ambientais no Brasil: da administração dos recursos naturais (1930) à criação do Sistema Nacional de Unidades de Conservação (2000). Desenvolvimento e Meio Ambiente, Paraná, n.24, p.71-82, 2011.

RÊGO, G. S.; PIMENTA, H. C. D.; SARAIVA, V. M.. Agenda ambiental na administração pública: A3P: um estudo sobre a potencialidade de aplicação no município de São Gonçalo do Amarante/RN. Holos, Rio Grande do Norte, v.27, n.4, p.2950, 2011.

ROCHA, E. P. M. R.. Programas de qualidade de vida no serviço público. In: BLIACHERIS, M. W.; FERREIRA, M. A. S. O.. Sustentabilidade na Administração Pública: valores e práticas de gestão socioambiental. Belo Horizonte: Fórum, 2012. p.107-130.

SANTANA, W. A.; MOURA, G. J. B.. Aplicação das diretrizes propostas pela Agenda Ambiental na Administração Pública. 
Revista Brasileira de Administração Científica, Aquidabã, v.5, n.1, p.307-315, 2014.

SANTILLI, J.. Socioambientalismo e novos direitos: proteção jurídica à diversidade biológica e cultural. São Paulo: Peirópolis, 2005.

SECCHI, L.. Políticas públicas: conceitos, esquemas de análise, casos práticos. São Paulo: Cengage Learning, 2010.

SOUSA, N. O. M.; SANTOS, F. R. P.; SALGADO, M. A. S.; ARAÚJO, F. F. S.. Dez anos de história: avanços e desafios do sistema nacional de unidades de conservação da natureza. In: MEDEIROS, R.; ARAÚJO, F. F. S.. Dez anos do sistema nacional de unidades de conservação da natureza: lições do passado, realizações presentes e perspectivas para o futuro. Brasília: MMA, 2011. p.9-19.
SOUZA, V. D.; UHLMANN, V. O.; PFITSCHER, E. D.. Sustentabilidade ambiental em instituição de ensino: aderência à Agenda Ambiental de Administração Pública. Revista Perspectivas Contemporâneas, Paraná, v.10, p.126$145,2015$.

VEIGA, J. E.. Do global ao local. Campinas: Armazém do Ipê, 2005.

VIEGAS, S. F. S. S.; CABRAL, E. R.; GOMES, S. C.; CARVALHO, A. C.. Agenda Ambiental na Administração Pública A3P: estudo da adesão e ação em uma universidade pública. Amazônia, Organizações e Sustentabilidade, Belém, v.4, n.2, p.7-28, 2015. 